\title{
Improving Frequency Stability of the Nigerian 330kv Transmission Network Using Fuzzy Controller
}

\author{
Ngang Bassey Ngang, Bakare Kazeem \\ Department of Electrical and Electronic Engineering, Faculty of Engineering, Enugu State University of Science and Technology (ESUT), \\ Enugu, Nigeria
}

Email address:

nbngang@gmail.com (N. B. Ngang)

To cite this article:

Ngang Bassey Ngang, Bakare Kazeem. Improving Frequency Stability of the Nigerian 330kv Transmission Network Using Fuzzy Controller. American Journal of Electrical Power and Energy Systems. Vol. 10, No. 3, 2021, pp. 43-50. doi: 10.11648/j.epes.20211003.12

Received: May 3, 2021; Accepted: May 20, 2021; Published: May 27, 2021

\begin{abstract}
The frequency instability observed in the power transmission network was mainly as a result of the per unit volts not falling within 0.95 through 1.05 P.U, volts. This has caused constant power failure in our transmission net work. This sad situation of power failure noticed in the power transmission network is contained by introducing an improvement in frequency stability of the Nigerian $330 \mathrm{kV}$ transmission network using fuzzy controller. It was achieved by first characterizing the $330 \mathrm{kv}$ transmission network by running load flow on the network, designing conventional SIMULINK model for improving frequency stability of the Nigerian $330 \mathrm{kv}$ transmission network, designing a rule base that makes these faulty buses to attain stability, integrating the designed rule to the conventional SIMULINK model for improving frequency stability of the Nigerian $330 \mathrm{kv}$ transmission network. The results obtained are conventional bus 1 per unit volts at $4 \mathrm{~s}$ through $10 \mathrm{~s}$ is 0.94 . On the other hand, when fuzzy controller is incorporated in the system it is 1.043P.U volts. This shows that there is frequency stability when fuzzy controller is incorporated in the system since the per unit volts fall within the range of 0.95 through 1.05 P.U. volt and conventional per unit volts is 0.944 which makes the frequency unstable since the volts does not attain stability. Meanwhile, when fuzzy controller is incorporated in the system the per unit volts is 1.047 . With these results, it shows that there is frequency stability when fuzzy controller is imbibed in the system. Since the per unit volt fall within the stability range of 0.95 through 1.05P.U. Volts.
\end{abstract}

Keywords: Improving, Frequency Stability, 330KV Transmission Network, Fuzzy Controller

\section{Introduction}

Nigerian national grid had experienced epileptic power supply for over a decade. The federal Government decided to privatize the generating and distribution sectors to improve performance and satisfy the consumers of electricity. This measure has not yielded considerable improvement due to technical reasons. The frequency instability observed in the power transmission network was mainly as a result of the per unit volts not falling within 0.95 through 1.05 P.U, volts. The research will seek to address the cause of instability and try to proffer solutions to the endemic complexity that has made industrialists to provide their individual generating plants. We have recorded incessant power failures for the last five years without any technical solution. The instability of system frequency and poor voltage profile had become an endemic complexity in our national grid. Power system stability is an important part of carrying out an assessment in transmission system security with a view to ensuring systems ability to withstand sudden disturbances under load application, switching operations, three phase short-circuit (symmetrical) faults, rotor angle swing/power frequency oscillations and loss of system elements when relay switch off affects some part of the network. In the electrical grid of today, there are many challenges ranging from changing generation landscape to increasing renewable energy inputs as well as remote power generations and aging $\mathrm{AC}$ transmission infrastructure with respect to ever increasing need for global demand for electricity. It is in the light of the foregoing that the need to enhance frequency stability of the Nigeria $330 \mathrm{kv}$ transmission network using ultra-capacitor has become expedient in this research. 


\section{Extent of Past Work}

For over a decade, transmission networks had been overloaded and are subjected closer to their stability limits. This is not unconnected with the increasing demand for electricity as a result of the growing population accompanied by industrialization. This could harm the power system security. Power system security in the real sense is the ability of the network to withstand disturbances without breaking down [1]. The key performance indices needed to assess the state of security of a power system is the transient stability [2] and it requires the ability of the power system to remain unaltered or in equilibrium and should return to an acceptable stability margin when there is a system surge or disturbance [3]. There are many methods of determining the transient instability in the power system which are numerical integration, direct method, a probabilistic method [4], and artificial intelligence methods such as artificial neural networks [5]. Recall that, transient stability is assessed by the system Critical Clearing Time (CCT) in response to system surge due to large disturbance such as faults, loss of large load, loss of generation, and major lines loss [6]. CCT gives the maximum duration of time a power system can remain stable under a given large disturbance condition [7]. The robustness of a power system is generally dependent on its response to disturbances. A higher value of CCT denotes a robust and better-secured system [8]. The level of network security is a factor that determines the level of integrity of a power system (i.e. transmission capability limit and flexibility of power system) [9]. Therefore, power system grid integrity can be enhanced by devising a means of improving Frequency stability [10]. Transmission Systems (FACTS) devices have been identified as cost-effective means of improving transient stability without the need for constructing new transmission lines [11]. Several devices have been proposed for improving the power system operation and they are [12]: the Static Var Compensator (SVC), Controllable Series Compensator (CSC), Phase Shifter (PS), Series Capacitors (SC), Thyristor Controlled Series Capacitors (TCSC), Unified Power Flow Controller (UPFC), Convertible Series Compensator (CSC), Inter-phase Power Flow Controller (IPFC), Static Synchronous Series Controller (SSSC), STATCOM, etc. Of these various FACTS devices, a suitable controller is desired

when appropriately sized [13]. A fuzzy controller is an effective means of regulating system frequency [14]. SVC serving alongside the Fuzzy controller would yield good results since they are shunt-connected and are usually installed at the midpoint of the transmission line or the line ends through a coupling transformer. It can improve transient stability by effectively controlling its reactive power output [15]. Nigeria power system is faced with series of technical challenges due to long, radial, weak, and aging transmission network

This present paper aims at investigating the improvement of the transient stability of the Nigerian $330 \mathrm{kV}$ transmission network by improving the frequency stability of the Nigerian $330 \mathrm{kV}$ Transmission Network using a Fuzzy controller. Appropriately sizing and locating SVC within the network can assist to get the expected improvement in the network. In this way, the security of the system is improved thereby challenging the need for immediate construction of new transmission lines. This would allow time for proper planning for a later upgrade

\section{Methodology}

\subsection{Characterization of 330kv Transmission Network by Running Load Flow on the Network.}

Methodology used to improve frequency stability of Nigeria 330Kk Transmission network using Fuzzy Controller followed the sequence of stated objectives from step 1 to step 5; the collection and tabulation of data as shown in Table 1 is the important step used to initiate the concept. The collection of data from the substation controlling the $330 \mathrm{kV}$ transmission line was by personal interview. The control room Operation engineers were interviewed and the reason for the work was explained in order to get access to classified data. The second step was the characterization of the network and performing load flow analysis on the network find the faulty buses whose per unit Volts did not fall within the range of 0.95 through 1.05 . The third step was the designing of a conventional SIMULINK model for improving frequency stability of the system or network. The fourth Step is the designing of a 'Rule base that makes these faulty buses to attain stability. The fifth and last stage is to integrate the designed rule to the conventional Simulink model for improving frequency stability of the national grid.

Table 1. 330kV Transmission network data collected from Newhaven Enugu transmission.

\begin{tabular}{|c|c|c|c|c|c|c|c|c|c|c|}
\hline Bus No & Bus code & P.U & Ang Deg & Load MW & Load Mvar & Gen MW & Gen Mvar & Inject Min & Inject Max & Inject Mvar \\
\hline 1 & 1 & 0.94 & 0 & 00.0 & 0.0 & 0.0 & 0.0 & 0 & 0 & 0 \\
\hline 2 & 0 & 0.91 & 0 & 00.0 & 0.0 & 0.0 & 0.0 & 0 & 0 & 0 \\
\hline 3 & 0 & 1.0 & 0 & 150.0 & 120 & 0.0 & 0.0 & 0 & 0 & 0 \\
\hline 4 & 0 & 1.0 & 0 & 0.0 & 0.0 & 0.0 & 0.0 & 0 & 0 & 0 \\
\hline 5 & 0 & 1.0 & 0 & 120.0 & 60 & 0.0 & 0.0 & 0 & 0 & 0 \\
\hline 6 & 0 & 1.0 & 0 & 140.0 & 90 & 0.0 & 0.0 & 0 & 0 & 0 \\
\hline 7 & 0 & 1.0 & 0 & 0.0 & 0.0 & 0.0 & 0.0 & 0 & 0 & 0 \\
\hline 9 & 0 & 1.0 & 0 & 80.0 & 50.0 & 0.0 & 0.0 & 0 & 0 & 0 \\
\hline 10 & 2 & 1.025 & 0 & 0.0 & 0.0 & 200 & 0.0 & 0 & 180 & 0 \\
\hline 11 & 2 & 1.05 & 0 & 0.0 & 0.0 & 160 & 0.0 & 0 & 120 & 0 \\
\hline
\end{tabular}


3.2. To Run the Load Flow of the Characterized Data to Find the Faulty Buses That Their P.U Volts Did Not Fall Within the Range of 0.95 Through 1.05 Thereby Making the Frequency Unstable

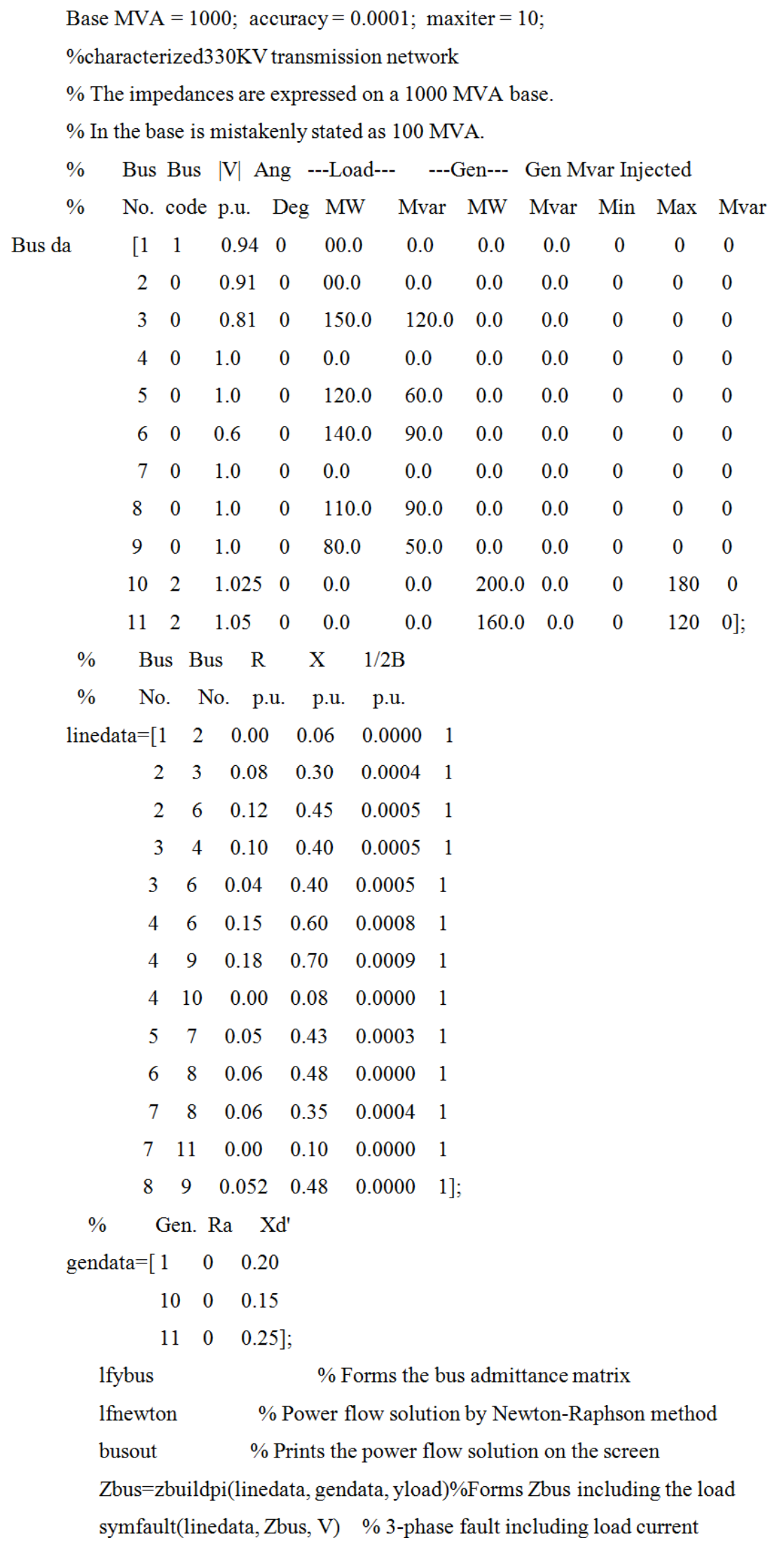

Figure 1. The load flow program that detects the fault buses did not fall within the stability range of 0.95 through 1.05P.U. Volts. 
Power Flow Solution by Newton-Raphson Method

Maximum Power Mismatch $=7.66819 \mathrm{e}-008$

No. of Iterations $=10$

Bus Voltage Angle

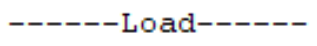

---Generation---

MW Mvar

Injected

No. Mag.

Degree

MU Mvar

251.879

$-15.338$

$\begin{array}{lr}0.940 & 0.000 \\ 0.941 & -0.979 \\ 0.933 & -3.642 \\ 0.993 & -3.173 \\ 0.965 & -9.271 \\ 0.934 & -4.530 \\ 0.999 & -6.380 \\ 0.947 & -6.695 \\ 0.944 & -6.447 \\ 1.015 & -2.264 \\ 1.020 & -5.480\end{array}$

0.000

0.000

0.000

0.000

0.000

0.000

0.000

0.000

0.000

0.000

150.000

120.000

0.000

0.000

0.000

0.000

0.000

0.000

0.000

0.000

120.000

60.000

0.000

0.000

0.000

140.000

90.000

0.000

0.000

0.000

0.000

0.000

0.000

0.000

0.000

110.000

50.000

0.000

0.000

0.000

0.000

200.000

277.500

0.000

0.000

160.000

215.327

0.000

0.000

0.000

0.000

Total

$600.000 \quad 410.000 \quad 611.879$

477.489

0.000

Figure 2. The load flow program results.

Figure 2 shows the load flow program results that detects the faulty buses that cause frequency instability. These faulty buses are 1, 2, 3, 6 and 9 that the per unit volt does not fall within 0.95 through 1.05 P.U volts. Their respective per unit volts are $0.940,0.9441,0.933,0.934$ and 0.944 P.U volts.

\subsection{To design Conventional SIMULINK Model for Improving Frequency Stability of the Nigerian 330kv Transmission Network}

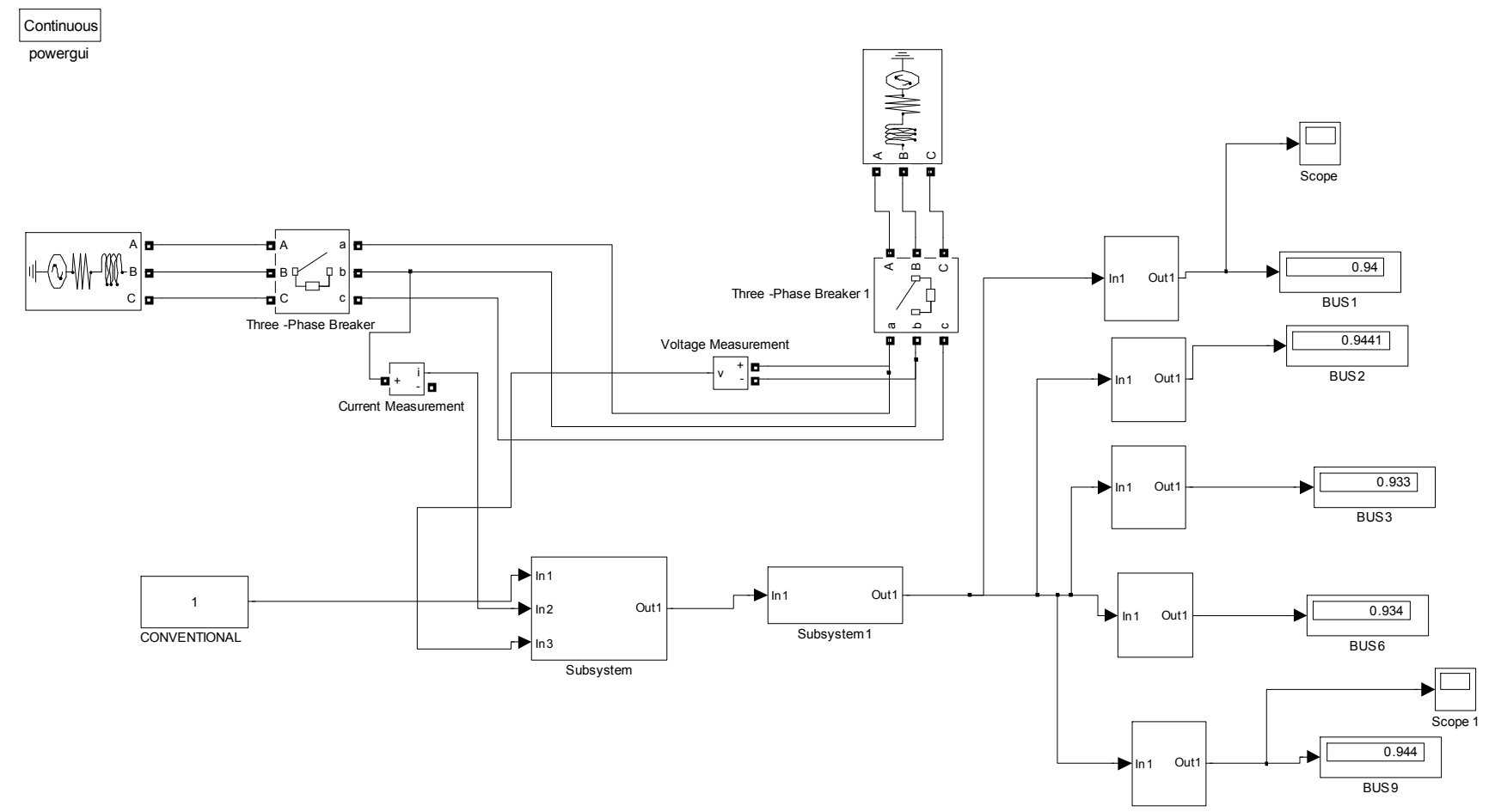

Figure 3. Designed conventional SIMULINK model for improving frequency stability of the Nigerian 330kv transmission network.

Figure 3 shows designed conventional SIMULINK model for improving frequency stability of the Nigerian 330kv transmission network. The result obtained are as shown in figures 6 and 7. 


\subsection{To Design a Rule Base That Makes These Faulty Buses to Attain Stability}

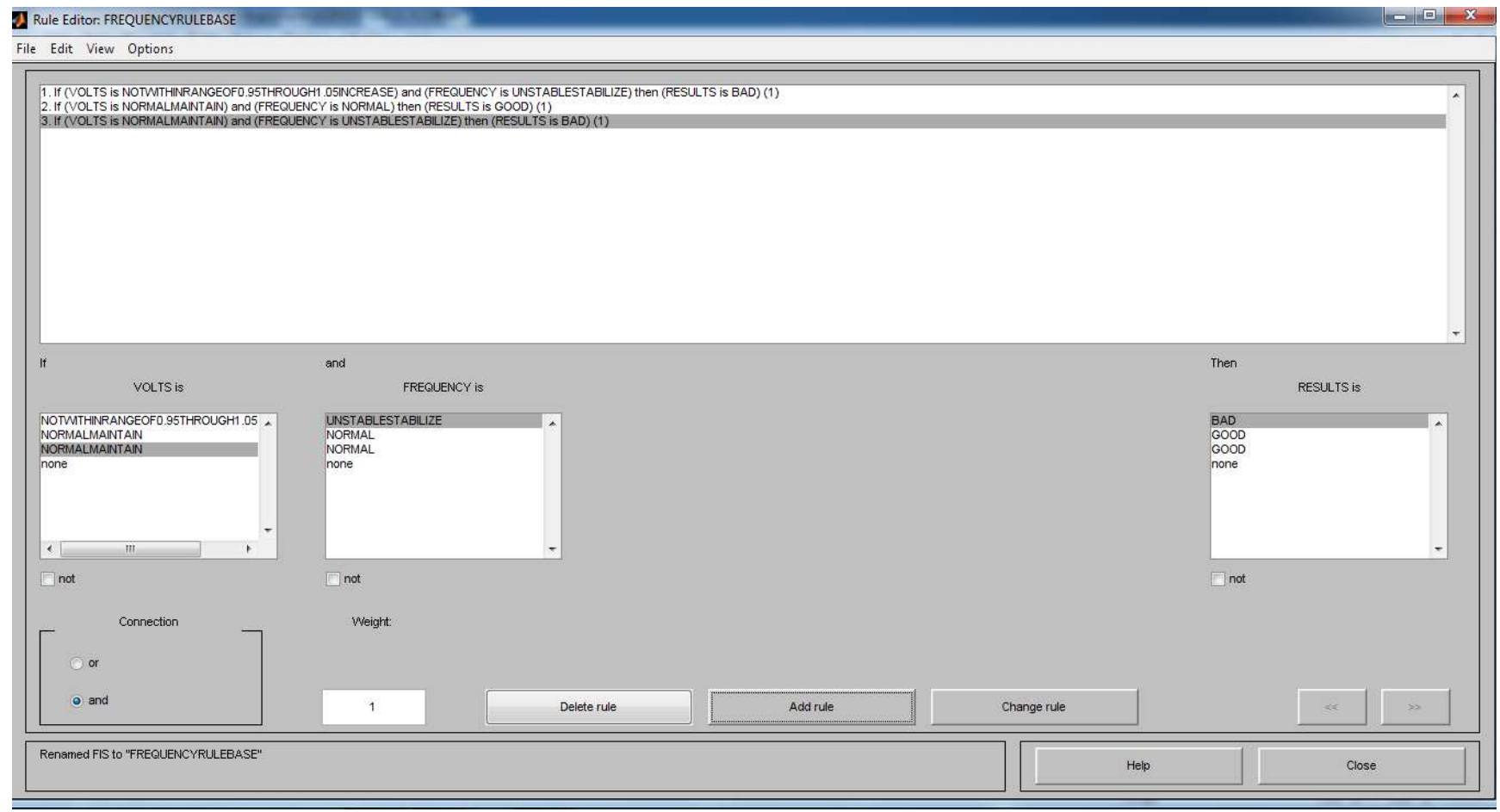

Figure 4. Designed rule base that makes these faulty buses to attain stability.

\subsection{To Integrate the Designed Rule to the Conventional SIMULINK Model for Improving Frequency Stability of the} Nigerian 330kv Transmission Network

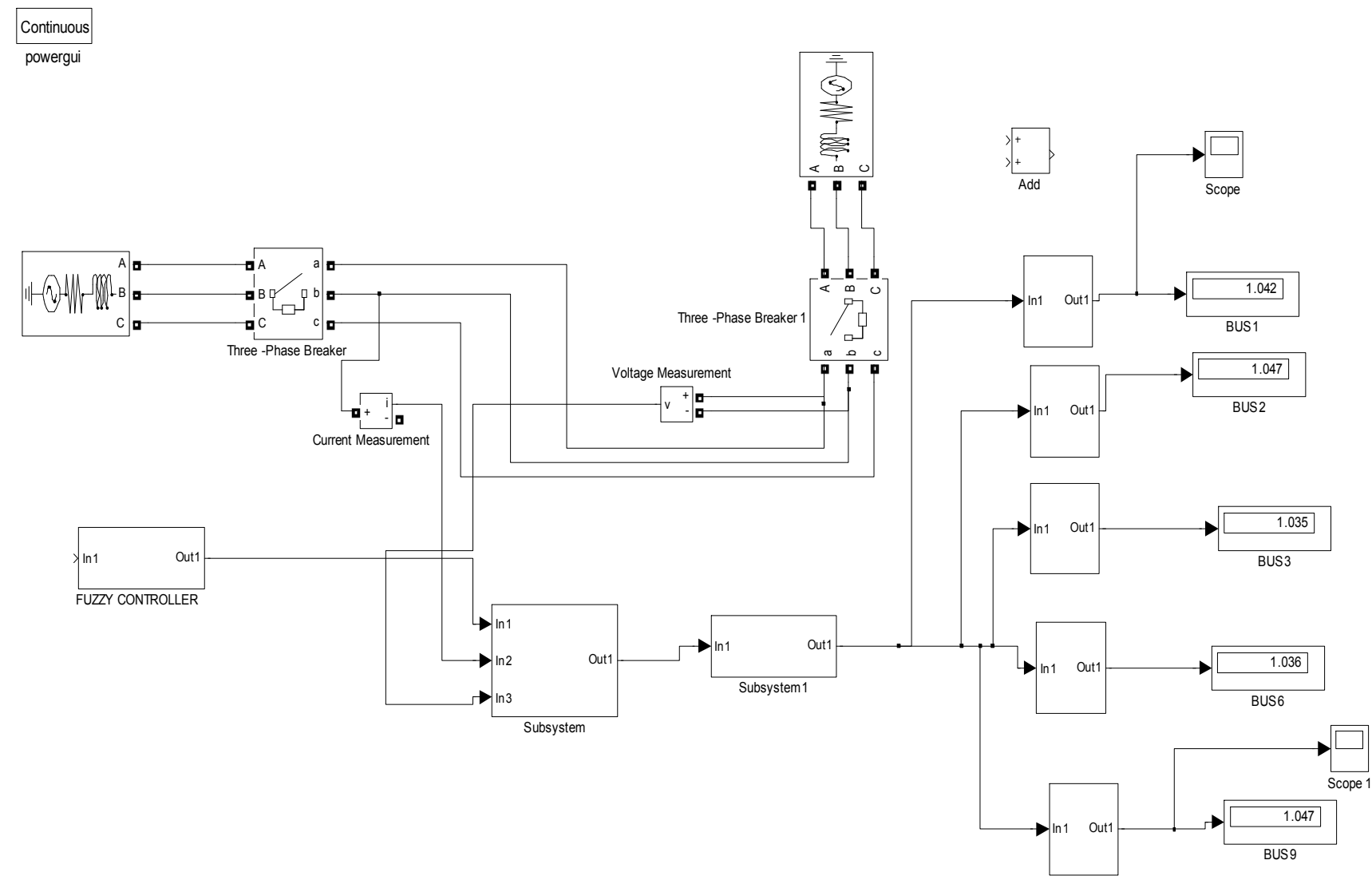

Figure 5. Integrated designed rule to the conventional SIMULINK model for improving frequency stability of the Nigerian 330kv transmission network. 


\section{Results and Discussion}

In Figure 1, the load flow program that detects the fault buses did not fall within the stability range of 0.95 through 1.05P.U. Volts.

Figure 2 shows the load flow program results that detects the faulty buses that cause frequency instability. These faulty buses are 1, 2, 3, 6 and 9 that the per unit volt does not fall within 0.95 through 1.05 P.U volts. Their per unit volts are $0.940,0.9441,0.933,0.934$ and 0.944 P.U volts.

Figure 3 shows designed conventional SIMULINK model for improving frequency stability of the Nigerian $330 \mathrm{kv}$ transmission network. The result obtained are as shown in figures 6 and 7. Figure 4 shows designed rule base that makes these faulty buses to attain stability. Figure 5 shows integrated designed rule to the conventional SIMULINK model for improving frequency stability of the Nigerian $330 \mathrm{kv}$ transmission network. The result obtained are shown in figures 6 and 7.

Figure 6 shows Comparison between conventional and fuzzy controller volts in improving frequency stability of the Nigerian $330 \mathrm{kv}$ transmission network in bus 1 . The conventional bus 1 per unit volts at 4 s through 10 s is 0.94 . On the other hand, when fuzzy controller is incorporated in the system it is 1.043P.U volts. This shows that there is frequency stability when fuzzy controller is incorporated in the system since the per unit volts fall within the range of 0.95 through 1.05 P.U. volt.

Figure 7 shows the Comparison between the conventional and fuzzy controller volts in improving frequency stability of the Nigerian $330 \mathrm{kv}$ transmission network in bus 9 . In figure 7 the conventional per unit volts is 0.944 which makes the frequency unstable since the volts does not attain stability. Meanwhile, when fuzzy controller is incorporated in the system the per unit volts is 1.047 . With these results, it shows that there is frequency stability when fuzzy controller is imbibed in the system. Since the per unit volt fall within the stability range of 0.95 through 1.05P.U. Volts.

Table 2. Comparing conventional and fuzzy controller volts in improving frequency stability of the Nigerian $330 \mathrm{kv}$ transmission network in bus 1.

\begin{tabular}{lll}
\hline Time (s) & Conventional BUS1 volts (P.U) & Fuzzy controller BUS1 volts (P.U) \\
\hline 0 & 0 & 0 \\
1 & 0.6 & 0.65 \\
2 & 0.8 & 0.9 \\
3 & 0.9 & 1 \\
4 & 0.94 & 1.043 \\
10 & 0.94 & 1.043 \\
\hline
\end{tabular}

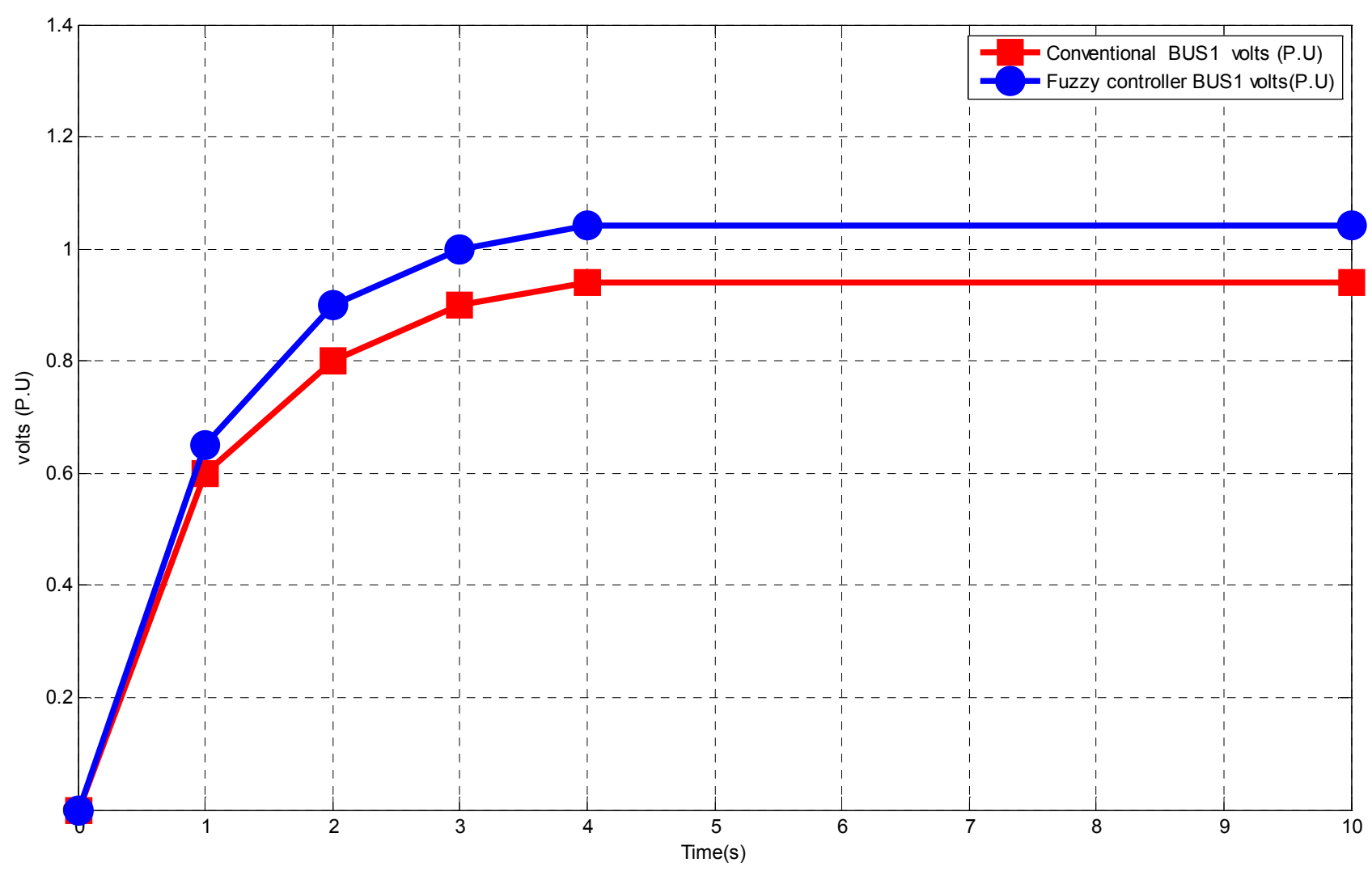

Figure 6. Comparing conventional and fuzzy controller volts in improving frequency stability of the Nigerian $330 \mathrm{kv}$ transmission network in bus 1. 
Table 3. Comparison between conventional and fuzzy controller volts in improving frequency stability network in bus 9

\begin{tabular}{lll}
\hline Time (s) & Conventional BUS9 volts (P.U) & Fuzzy controller BUS9 volts (P.U) \\
\hline 0 & 0 & 0 \\
1 & 0.6 & 0.65 \\
2 & 0.8 & 0.9 \\
3 & 0.9 & 1 \\
4 & 0.944 & 1.047 \\
10 & 0.944 & 1.047 \\
\hline
\end{tabular}

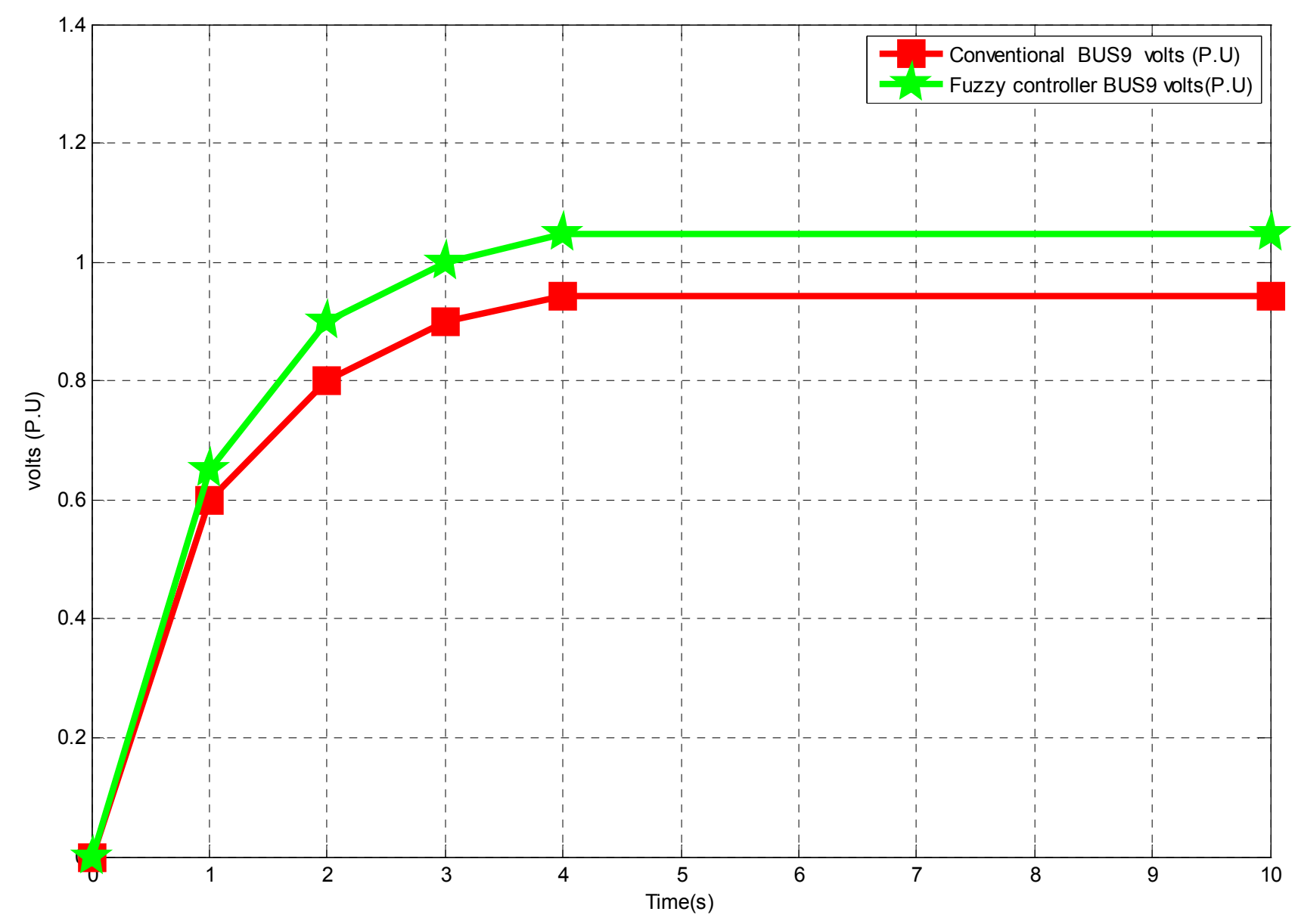

Figure 7. Comparing conventional and fuzzy controller volts in improving frequency stability of the Nigerian 330kv transmission network in bus 9

\section{Conclusion}

The frequency in stability in the transmission network has arisen as a result of per unit volts not falling within the range of 0.95 through 1.05P.U. volts. This frequency instability cause, intermittent power supply. This is overcome by improving frequency stability of the Nigerian $330 \mathrm{kv}$ transmission network using fuzzy controller, It is done in this manner, characterizing $330 \mathrm{kv}$ transmission network by running load flow on the network, designing conventional SIMULINK model for improving frequency stability of the Nigerian $330 \mathrm{kv}$ transmission network, designing a rule base that makes these faulty buses to attain stability, integrating the designed rule to the conventional SIMULINK model for improving frequency stability of the Nigerian $330 \mathrm{kv}$ transmission network. The results obtained are conventional bus 1 per unit volts at 4 s through 10 s is 0.94 . On the other hand, when fuzzy controller is incorporated in the system it is 1.043P.U volts. This shows that there is frequency stability when fuzzy controller is incorporated in the system since the per unit volts fall within the range of 0.95 through 1.05 P.U. volt and conventional per unit volts is 0.944 which makes the frequency unstable since the volts does not attain stability. Meanwhile, when fuzzy controller is incorporated in the system the per unit volts is 1.047 . With these results, it shows that there is frequency stability when fuzzy controller is imbibed in the system. Since the per unit volt fall within the stability range of 0.95 through 1.05P.U. Volts.

\section{Acknowledgements}

Appreciation goes to the Faculty of Engineering, Enugu State University of Science and Technology for the use of resource materials necessary for the completion of this 
research work. This work is assisted by Ngatek Global Services Limited, a private company based in Cross River State, Nigeria whose corporate objective is to support and provide funds for research works.

\section{References}

[1] Ayodele, T. R., Ogunjuyigbe, A. S. and Oladde, O. O (2016). 'Improving the Transient Stability of Nigeria $330 \mathrm{kv}$ Transmission Network using Statistic VAR Compensation Part 1'. The Base study. Vol 35, No. 1, Pp 155-166.

[2] Olaiga, B. O. and Olulope, P. K. (2019). 'Voltage Stability in Nigeria Power Grid.’ A detailed Literature Review, Vol. 2 issu1, Pp 1-10.

[3] Nkan, I. E., Okoro, O. I., Awali, C. C. and Akuru, U. B. (2019). 'Investigating the Dynamic Stability of the Nigeria 48Bus system using FACTs Devices'. Vol. 38, No. 3, Pp 732743.

[4] Okakwu, I. K., Alayande, A. S., Agbontaen, F. O. and AdeIkuesan, O. O. (2019). 'Comparative Study of TCSC and RSFCL for Transient Stability Enhancement of the Nigeria 330kv Transmission Network'. Vol. 5, No. 3 Pp 161-174.

[5] Egido, T., Sigrist, L., Lobato, E. and Rouco, L. (2015). 'Energy Storage systems for Frequency Enhancement in Small-Isolated Power Syatem'. Vol. 1, No. 13, Pp 820-825.

[6] Barath, T. and Regupathic, M. (2015). 'Super Capacitor Based Power Conditioning System for Power Quality Improvement in Industries.' Vol. 4, ISSN. 2278-0181 Pp 64-650.

[7] Okwe. G. I., Akwukwaegbu, I. O., Uneze, I. M., Nwaogwugwu, and Nnanyereugo, C. (2015). 'Voltage Stability Improvement of Power Transmission System in Nigeria using TCSC'. Vol. No. 1, Pp 1-15.
[8] Mathew, S., Wara, S. T., Adejumobi, A., Ajisegiri, E. S. A. and Olanipekun, A. J. (2014). 'Power System's voltage Stability Improvement using Static Varcompensator., Vol. 4., ISSUE 1. PP 494-501.

[9] Bashar, S. A. and Chin, K. G (2016). 'Power System Frequency Stability and Control': Survey. Vol. 11, No. 8, Pp 5688-5695.

[10] Md Salah, E. S., Mahmud-UI-Tarik, C. and MdJanatul, F. (2017). 'An overview of Frequency Control as a Criteria of Power System Reliability and International survey of Determining Operating Reserve'. Vol. 3, No. 5, Pp 101-114.

[11] Jag, P. and Pardeep, N. (2018). 'A survey on Load Frequency Control (LFC) Problem in Hybrid Power System'. Vol. 4, Issue 8, PP 229-234.

[12] Braide, S. L. and Diema, E. J. (2018). Analysis of Steady and Transients-state Stability of Transmission Network.'Vol. 6, No. 5, ISSN 2309-2405.

[13] Akinloye, B. O. Osherire, P. O. and Epemu, A. M. (2018). 'Optimized Coordinated control of LFC and SMES to enhance Frequency Stability of a real Multi-source Power System Considering high renewable energy penetration'. Vol. 3, No. 39, Pp 1-15.

[14] Zeyad, A. O., Liena, M. C, Lahieb, A., Mazin, T. M. (2019). 'Frequency Control of future power system, Reviewing and Evaluating Challenges and New Methods'. Vol. 7, No. 1, PP 9-25.

[15] Reza, K. G., Mohammad, R. A. and Mohsen, F. C. (2017). 'Control Strategies for Enhancing Stability by DFIFs in a Power System with High percentage of Wind Power Penetration'. Vol., No. 1140, Pp 1-15. 